\section{An Apple computer program for hierarchical grouping analysis}

MARLEY W. WATKINS

SouthWest EdPsych Services, Inc., Phoenix, Arizona

and

\section{JOSEPH C. KUSH}

Deer Valley Unified School District, Phoenix, Arizona

Cluster or grouping analysis is a multivariate statistical procedure designed to create homogeneous groups. In hierarchical grouping, a series of score profiles are compared (across a series of variables) and progressively grouped into a smaller number of mutually exclusive groups, each having members that are as much alike as possible. Hierarchical grouping is an efficient means of uncovering structure in data and makes it easier to consider and understand relations among subjects and variables. It also allows the formation of objective classifications of subjects.

Most comparisons of clustering techniques provide evaluations of the precision with which each technique recovers the known structure of data sets (Aldenderfer \& Blashfield, 1984). Ward's (1963) algorithm has been identified as a preferred method of cluster analysis for typical behavioral science data (Blashfield, 1976; Kuiper \& Fisher, 1975; Morey, Blashfield, \& Skinner, 1983). Ward's method uses Euclidean distance measures and attempts to minimize the within-group variance. It has been coded into a FORTRAN program by Veldman (1967) and

J. C. Kush's mailing address is: Deer Valley School District, 20402 N. 15th Avenue, Phoenix, AZ 85027. is available in statistical packages which operate on mainframe computers. In this article we present an adaptation of Veldman's (1967) program written in BASIC for an Apple microcomputer.

Program Description. HGROUP90N is written in Applesoft BASIC and requires 64K RAM under the DOS 3.3 operating system. The programs accommodate up to 90 subjects and 20 variables. Data may be input from the keyboard or from disk and may be stored on disk. Keyboard input is fully interactive and allows editing and review of data. Printed output includes a list of variables, group combinations, cluster membership identifications, and error terms associated with each grouping. Complete instructions and references are provided on the program disk.

Program Availability. HGROUP90N is available on disk by sending $\$ 6$, to cover postage and reproduction costs, to J. C. Kush. Requests from outside the United States should include $\$ 8$ for costs and airmail delivery.

\section{REFERENCES}

Aldenderfer, M. S., \& Blashfield, R. K. (1984). Cluster analysis. Beverly Hills: Sage.

Blashfield, R. K. (1976). Mixture model tests of cluster analysis: Accuracy of four agglomerative hierarchical methods. Psychological Bulletin, 83, 377-388.

Kuiper, F., \& Fisher, L. (1975). A Monte Carlo comparison of six clustering procedures. Biometrics, 31, 777-783.

Morey, L. C., Blashfield, R. K., \& Skinner, H. A. (1983). A comparison of cluster analysis techniques within a sequential validation framework. Multivariate Behavioral Research, 18, 309-329.

VELDMAN, D. J. (1967). FORTRAN programming for the behavioral sciences. New York: Holt, Rinehart and Winston.

WARD, J. (1963). Hierarchical grouping to optimize an objective function. Journal of the American Statistical Association. 58, 236-244.

(Revision accepted for publication July 11, 1985.) 